\title{
Intuition based Decision Methodology for Ranking Interval Type - II Fuzzy Numbers
}

\author{
Ahmad Syafadhli Abu Bakar ${ }^{1}$ Alexander Gegov ${ }^{1}$ \\ ${ }^{1}$ School of Computing, University of Portsmouth, Buckingham Building, Portsmouth PO1 3HE, United Kingdom.
}

\begin{abstract}
Type - II fuzzy number is introduced in decision making analysis as a concept that is capable to effectively deal with uncertainty in the information about a decision. As type - II fuzzy number is represented by possibility distribution, it is hard to determine which type II fuzzy number is greater than the other. In this paper, a new methodology for ranking type - II fuzzy number is proposed. The methodology is made up based on two intuitionistic components namely centroid point and spread. The paper also introduces for the first time the extension of type - II fuzzy number into standardised generalised type - II fuzzy number so that the representation is more generic and applicable to any cases of decision making problems. The methodology is then validated using both theoretical and empirical validations for real decision making applications.
\end{abstract}

Keywords: Interval type - II fuzzy number; ranking interval type - II fuzzy number; standardised generalised interval type - II fuzzy numbers; consistent with human intuition.

\section{Introduction}

Fuzzy number is often used as a great tool in human decision making. This is reflected by its capability to appropriately representing linguistic characteristics used by human when making a decision. Apart from that, it complements any imprecision and incompleteness in the information which contributes to uncertainty towards decision informativeness. These evidences emphasis that fuzzy number introduced by Zadeh (1965) is an appropriate tool for decision making especially when dealing with imprecise numerical quantities and subjective preferences of decision makers (Deng, 2013).

According to Zimmerman (2000) and Kumar et al. (2010), fuzzy numbers are represented by possibility distributions, thus they might potentially overlap with each other. If they are overlapped, then it is not easy to clearly determine which fuzzy number is larger or smaller than another (Kumar et al. (2010). In order to differentiate fuzzy numbers appropriately, a ranking fuzzy numbers concept is introduced by Jain (1976) such that it is regarded as a concept that is suitable in decision making application. In the literature of ranking fuzzy numbers, main processes involve in ranking fuzzy numbers are evaluating all fuzzy numbers under consideration and comparing them based on certain preferences. These indicate that practitioner cannot use direct evaluation towards fuzzy numbers if effective decision making is targeted to achieve. Among established methods for ranking fuzzy numbers found in the literature of fuzzy sets are Cheng (1998), Chu \& Tsao (2002), Wang et al., (2005), Asady (2010), Bakar et al., (2010; 2012), Dat et al. (2012), Yu et al. (2013) and Bakar \& Gegov (2014).

Although, ranking fuzzy numbers concept is developed for decision making purposes, limitation of fuzzy number itself on representing the uncertainty satisfactorily, affects the final outcome of a decision making. This is because fuzzy numbers consider only one kind of uncertainty which is the intra - personal uncertainty in representing linguistic characteristics whilst there are supposedly two kinds of uncertainties that are related to linguistic characteristics namely intra - personal uncertainty and inter - personal uncertainty (Wallsten \& Budescu, 1995). Due to the fact that the uncertainty representation of fuzzy number is arguable, capability of fuzzy numbers is extended to type - II fuzzy number (Zadeh, 1975) so that both kinds of uncertainty namely intra and inter - personal uncertainties are well represented. Since, type - II fuzzy number is an extension of fuzzy numbers, hence the term type - I fuzzy numbers is used to replace the term fuzzy numbers for convenience purposes. Another advantage of type - II fuzzy number than type - I fuzzy number is it provides more flexibility in terms of degree of freedom than the latter as two type - I fuzzy numbers are utilised as a type - II fuzzy number. Those type - I fuzzy numbers charaterise the two kinds of uncertainty using two membership functions known as the primary and secondary ( $\mathrm{Hu}$ et al., 2013).

Investigation on utilising type - II fuzzy numbers is not new in the literature of fuzzy sets as many decisions involving them are found in various decision making problems. For example, radiographic tibia image clustering (John et al., 2000), signal processing problem (Nagy \& Takács, 2008), pattern recognition (Wu \& Mendel, 2009) and oversea minerals investment problem (Hu et al., 2013). Even though, type - II fuzzy number improves the capability of type - I fuzzy number, it needs a suitable method to distinguish it from other type - II fuzzy numbers when there are more than two type - II fuzzy numbers are considered at a time. As type - II fuzzy number is a generalisation of type - I fuzzy numbers (Mitchell, 2006) and is viewed as a group of type - I fuzzy numbers where each of the two aforementioned kinds of uncertainties are modelled us- 
ing type - I fuzzy numbers, it requires a ranking method like type - I fuzzy numbers as it also represented by possibility distribution.

Due to this, the paper suggests a new decision methodology for ranking type - II fuzzy numbers based on centroid point and spread. Both methods are chose and utilised in this study because these methods capable to give appropriate decision results such that the results are consistent with human intuition (Bakar \& Gegov, 2014). In this methodology, interval type - II fuzzy number is used as it is viewed as a special case and requires less computational works compared to type - II fuzzy numbers (Hu et al., 2013). Along with this study, an extension of type - II fuzzy numbers into standardised generalised type - II fuzzy numbers is introduced for the first time in the literature of fuzzy sets due to the extension creates generic representation of type - II fuzzy numbers which are suitable for decision making purposes.

The remainder of the paper is organised as follows: Section 2 discusses the theoretical preliminaries, Section 3 views on the proposed work. Validation of the proposed work is given in Section 4 and at last, a conclusion is made in section 5 .

\section{Theoretical Preliminaries}

The following are some basic concepts used in this paper.

\subsection{Type - I trapezoidal fuzzy number}

A type - I trapezoidal fuzzy numbers can be represented by the following membership function given by

$$
\mu_{A_{i}}(x)=\left(a_{i 1}, a_{i 2}, a_{i 3}, a_{i 4}\right)=\left\{\begin{array}{cll}
\frac{x-a_{i 1}}{a_{i 2}-a_{i 1}} & \text { if } & a_{i 1} \leq x \leq a_{i 2} \\
1 & \text { if } & a_{i 2} \leq x \leq a_{i 3} \\
\frac{a_{i 4}-x}{a_{i 4}-a_{i 3}} & \text { if } & a_{i 3} \leq x \leq a_{i 4} \\
0 & \text { otherwise }
\end{array}\right.
$$

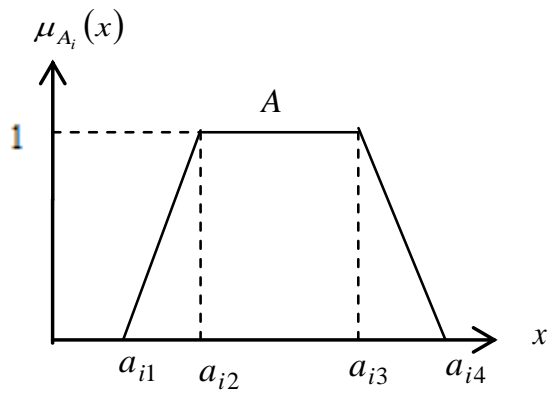

Fig 1: Type - I Fuzzy Number

For a type - I trapezoidal fuzzy number, if $a_{i 2}=a_{i 3}$, then the type - I fuzzy number is in the form of type - I triangular fuzzy number. Whereas, if $a_{i 1}=a_{i 2}=a_{i 3}=a_{i 4}$ for both type - I triangular and type - I trapezoidal fuzzy numbers, then both type - I fuzzy numbers are said to be in the form of type - I singleton fuzzy number. Length between $a_{i 1}$ and $a_{i 4}$ is known as the core of the type - I fuzzy numbers (Chen \& Chen, 2009).

\subsection{Standardised generalised type - I trapezoidal fuzzy number}

If type - I fuzzy number $A$ has the property such that $-1<a_{i 1}<a_{i 2}<a_{i 3}<a_{i 4}<1$ then $\tilde{A}$ is called a standardised generalised type - I trapezoidal fuzzy number and is denoted as (Chen \& Chen, 2009)

$$
\tilde{A}=\left(\tilde{a}_{i 1}, \tilde{a}_{i 2}, \tilde{a}_{i 3}, \tilde{a}_{i 4} ; w_{\tilde{A}}\right)
$$

Furthermore if $\tilde{a}_{i 2}=\tilde{a}_{i 3}$ then $\tilde{A}$ is known as a standardised generalised type - I triangular fuzzy number. Any generalised type - I fuzzy number may be transformed into a standardised generalised type - I fuzzy numbers by normalization as described in (2).

$$
\begin{aligned}
\tilde{A} & =\left(\frac{a_{i 1}}{|k|}, \frac{a_{i 2}}{|k|}, \frac{a_{i 3}}{|k|}, \frac{a_{i 4}}{|k|} ; w_{A}\right) \\
& =\left(\tilde{a}_{i 1}, \tilde{a}_{i 2}, \tilde{a}_{i 3}, \tilde{a}_{i 4} ; w_{\tilde{A}}\right)
\end{aligned}
$$

where $|k|=\max \left(a_{i 1}, a_{i 2}, a_{i 3}, a_{i 4}\right)$.

It should be noted that in the normalisation process only the components of type - I fuzzy numbers are changed where $a_{i 1}, a_{i 2}, a_{i 3}, a_{i 4}$ are changed to $\tilde{a}_{i 1}, \tilde{a}_{i 2}, \tilde{a}_{i 3}, \tilde{a}_{i 4}$ but the height, $w_{A}$ of the type - I fuzzy number remains unchanged (Chen \& Chen, 2009).

\subsection{Interval Type - II fuzzy numbers}

As mentioned in the introduction section, a type - II fuzzy number consists of primary and secondary membership functions where both are extensions of type - I fuzzy numbers. Based on Mendel et al. (2006), type - II fuzzy number is defined as follows.

(Mendel et al., 2006) Let $\hat{A}$ be a type - II fuzzy set, i.e.

$\hat{A}=\left\{((x, u),) \mu_{\hat{A}}(x, u) \mid \forall x \in X, \forall u \in J_{x} \subseteq\left[0,1,0 \leq \mu_{A^{\prime}} \leq 1\right]\right\}$

where $X$ and $\mu_{A^{\prime}}$ denote the domain of $\hat{A}$ and the membership functions of $\hat{A}$ respectively.

$A^{\prime}$ can also be expressed as

$\hat{A}=\int_{x \in X} \int_{\mu \in J_{x}} \mu_{\hat{A}}(x, u) /(x, u), J_{x} \subseteq[0,1]$

If all values of membership grade, $\mu_{A^{\prime}}(x, u)=1$, the type - II fuzzy set is called interval type - II fuzzy set, i.e.,

$\hat{A}=\int_{x \in X} \int_{\mu \in J_{x}} 1 /(x, u), J_{x} \subseteq[0,1]$ 
Therefore, without loss of generality, the interval type II fuzzy number is called trapezoidal interval type - II fuzzy numbers when upper membership function (secondary) and lower membership function (primary) are depicted as

$$
\hat{A}=\left[\left(\hat{a}_{1}^{U}, \hat{a}_{2}^{U}, \hat{a}_{3}^{U}, \hat{a}_{4}^{U} ; 1 ; 1\right),\left(\left(\hat{a}_{1}^{L}, \hat{a}_{2}^{L}, \hat{a}_{3}^{L}, \hat{a}_{4}^{L} ; w_{\hat{a}}^{L} ; w_{\hat{a}}^{L}\right)\right)\right]
$$

where $\hat{a}_{i}^{U}, i=1,2,3,4$ and $\hat{a}_{i}^{L}, i=1,2,3,4$ are secondary and primary membership functions values for $\hat{A}$, whereas, $w_{\hat{a}}^{L}$ is the height for the primary membership function.

$$
\mu_{\hat{A}}(x)
$$

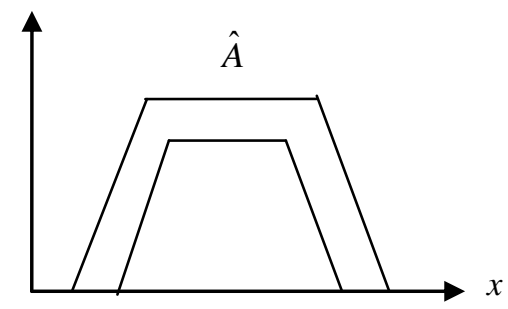

$$
\hat{A}=\left[\left(\hat{a}_{1}^{U}, \hat{a}_{2}^{U}, \hat{a}_{3}^{U}, \hat{a}_{4}^{U} ; 1 ; 1\right),\left(\left(\hat{a}_{1}^{L}, \hat{a}_{2}^{L}, \hat{a}_{3}^{L}, \hat{a}_{4}^{L} ; w_{\hat{a}}^{L} ; w_{\hat{a}}^{L}\right)\right)\right]
$$

Fig 2: An Interval Type - II Fuzzy Numbers

\section{Methodology for Ranking Type - II Fuzzy Num- bers}

\subsection{Standardised generalised interval type - II fuzzy number}

As mentioned in the introduction section, this study proposes a concept of standardised generalised interval type - II fuzzy number for easy computation. This is because it provides generic representation of interval type - II fuzzy numbers that are suitable for decision making purposes. Thus, definition of standardised generalised interval type - II fuzzy number is given as the following.

If an interval type - II fuzzy number $\hat{A}$ has the property such that $-1<a_{1}^{\prime U}<a_{2}^{\prime U}<a_{3}^{\prime U}<a_{4}^{\prime U}<1$ and $-1<a_{1}^{\prime L}<a_{2}^{\prime L}<a_{3}^{\prime L}<a_{4}^{\prime L}<1$ then $A^{\prime}$ is called as a standardised generalised interval type - II trapezoidal fuzzy number and is denoted as

$$
A^{\prime}=\left[\left(a_{1}^{\prime U}, a_{2}^{\prime U}, a_{3}^{\prime U}, a_{4}^{\prime U} ; 1 ; 1\right),\left(\left(a_{1}^{\prime L}, a_{2}^{\prime L}, a_{3}^{\prime L}, a_{4}^{\prime L} ; w_{a}^{L} ; w_{a}^{L}\right)\right)\right](4)
$$

Any interval type - II fuzzy numbers may be transformed into a standardised generalised interval type - II fuzzy numbers by normalization as described in (5).

$$
A^{\prime}=\left[\left(\frac{\hat{a}_{1}^{U}}{|k|}, \frac{\hat{a}_{2}^{U}}{|k|}, \frac{\hat{a}_{3}^{U}}{|k|}, \frac{\hat{a}_{4}^{U}}{|k|} ; 1 ; 1\right),\left(\left(\frac{\hat{a}_{1}^{L}}{|m|}, \frac{\hat{a}_{2}^{L}}{|m|}, \frac{\hat{a}_{3}^{L}}{|m|}, \frac{\hat{a}_{4}^{L}}{|m|} ; w_{\hat{a}}^{L} ; w_{\hat{a}}^{L}\right)\right)\right]
$$

$$
=\left[\left(a_{1}^{\prime U}, a_{2}^{\prime U}, a_{3}^{\prime U}, a_{4}^{\prime U} ; 1 ; 1\right),\left(\left(a_{1}^{\prime L}, a_{2}^{\prime L}, a_{3}^{\prime L}, a_{4}^{\prime L} ; w_{a}^{L} ; w_{a}^{L}\right)\right)\right\rfloor
$$

$$
\begin{aligned}
\text { where }|k| & =\max \left(\hat{a}_{1}^{U}, \hat{a}_{2}^{U}, \hat{a}_{3}^{U}, \hat{a}_{4}^{U}\right) \\
|m| & =\max \left(\hat{a}_{1}^{L}, \hat{a}_{2}^{L}, \hat{a}_{3}^{L}, \hat{a}_{4}^{L}\right)
\end{aligned}
$$

It should be noted that the normalisation process only changes the components of interval type - II fuzzy numbers where $\hat{a}_{1}^{U}, \hat{a}_{2}^{U}, \hat{a}_{3}^{U}, \hat{a}_{4}^{U}$ and $\hat{a}_{1}^{L}, \hat{a}_{2}^{L}, \hat{a}_{3}^{L}, \hat{a}_{4}^{L}$ are changed to $a_{1}^{\prime U}, a_{2}^{\prime U}, a_{3}^{\prime U}, a_{4}^{\prime U}$ and $a_{1}^{\prime L}, a_{2}^{\prime L}, a_{3}^{\prime L}, a_{4}^{\prime L}$ respectively while the heights, 1 and $w_{a}^{L}$, of type - II fuzzy number remain unchanged.

\subsection{Ranking of interval type - II fuzzy numbers based on centroid point and spread}

Let $A^{\prime}$ be a standardised generalised interval type - II fuzzy number denotes as

$$
A^{\prime}=\left[\left(a_{1}^{\prime U}, a_{2}^{\prime U}, a_{3}^{\prime U}, a_{4}^{\prime U} ; 1 ; 1\right),\left(\left(a_{1}^{\prime}{ }^{L}, a_{2}^{\prime L}, a_{3}^{\prime L}, a_{4}^{\prime L} ; w_{a}^{L} ; w_{a}^{L}\right)\right)\right]
$$

Then, the proposed methodology for ranking interval type - II fuzzy numbers is as follows.

Step 1: Compute the centroid point for $A^{\prime}$ by finding the horizontal $-x$ centroid of $A^{\prime}$ using

$$
x_{A^{\prime}}^{*}=\frac{\int_{-\infty}^{\infty} x f(x) d x}{\int_{-\infty}^{\infty} f(x) d x}
$$

and the vertical - y centroid equation $A^{\prime}$ as

$$
y_{A^{\prime}}^{*}=\frac{\int_{0}^{w_{A^{\prime}}} \alpha\left|A^{\prime}\right| d \alpha}{\int_{0}^{w_{A^{\prime}}}\left|A^{\prime}\right| d \alpha}
$$

where

$\left|A^{\prime}\right|$ is the length of the $\alpha$-cuts of $A^{\prime}$

$x_{A^{\prime}}^{*} \in[-1,1]$ and $y_{A^{\prime}}^{*} \in\left[0, w_{A^{\prime}}\right]$.

In this step, two centroid points are obtained for $A^{\prime}$ whereby the centroid points are $\left(x_{A_{U}^{\prime}}^{*}, y_{A_{U}^{\prime}}^{*}\right)$ and $\left(x_{A_{L}^{\prime}}^{*}, y_{A_{L}^{\prime}}^{*}\right)$ for $a_{i}$ and $b_{i}$ respectively.

Step 2: Calculate the spread value for $A^{\prime}$ such that the distance along the $x$ - axis from centroid of $x$-value is

$$
\begin{aligned}
i_{A^{\prime}} & =\operatorname{dist}\left[\left(a_{4}^{\prime}-a_{1}^{\prime}\right),\left(b_{4}^{\prime}-b_{1}^{\prime}\right)\right] \\
& =\left[\left|a_{4}^{\prime} U-x_{A_{U}^{\prime}}^{*}\right|+\left|x_{A_{U}^{\prime}}^{*}-a_{1}^{\prime} U\right|,\left|a_{4}^{\prime L}-x_{A_{L}^{\prime}}^{*}\right|+\left|x_{A_{L}^{\prime}}^{*}-a_{1}^{\prime}{ }^{L}\right|\right] \\
& =\left[\left|a_{4}^{\prime} U-a_{1}^{\prime}\right|,\left|a_{4}^{\prime L}-a_{1}^{\prime}{ }^{L}\right|\right]
\end{aligned}
$$


While the distance along the vertical $y$ - axis from the centroid of $y$-value is depicted as

$$
i i_{A^{\prime}}=y_{A_{U}^{\prime}}^{*}, y_{A_{L}^{\prime}}^{*}
$$

Therefore, spread of $A^{\prime}, s\left(A^{\prime}\right)$ is defined as

$$
\begin{aligned}
s\left(A^{\prime}\right) & =i_{A^{\prime}} \times i i_{A^{\prime}} \\
& =\left(\left|a_{4}^{\prime}{ }^{\prime}-a_{1}^{\prime}{ }^{U}\right| \times y_{A_{U}^{\prime}}^{*}\right),\left(\left|a_{4}^{\prime}{ }^{L}-a_{1}^{\prime}{ }^{L}\right| \times y_{A_{L}^{\prime}}^{*}\right)
\end{aligned}
$$

where $i_{A^{\prime}}$ and $i i_{A^{\prime}}$ are dist $\left[\left(a_{4}^{\prime} U-a_{1}^{\prime} U\right),\left(a_{4}^{\prime}{ }^{L}-a_{1}^{\prime}{ }^{L}\right)\right\rfloor$ and $y_{A_{U}^{\prime}}^{*}, y_{A_{L}^{\prime}}^{*}$ respectively. $s\left(A^{\prime}\right), i_{A^{\prime}}$, $i i_{A^{\prime}}$, dist $\left(a_{4}^{\prime}-\right.$ $\left.a_{1}^{\prime}\right) \in[0,1]$.

It has to be noted that this step also produces two values like Step 1 but in this case, both values are spread for $a_{4}^{\prime U}$ and $a_{4}^{\prime L}$ which are separating by ','.

Step 3: Determine the ranking value for $A^{\prime}$ using the following equation

$$
\operatorname{CPS}_{I I}\left(A^{\prime}\right)=x_{A^{\prime}}^{*} \times y_{A^{\prime}}^{*} \times\left(1-s\left(A^{\prime}\right)\right)
$$

where

$x_{A^{\prime}}^{*}$ is the average value of $x_{A_{U}^{\prime}}^{*}$ and $x_{A_{L}^{\prime}}^{*}$

$y_{A^{\prime}}^{*}$ is the average value of $y_{A_{U}^{\prime}}^{*}$ and $y_{A_{L}^{\prime}}^{*}$

$s\left(A^{\prime}\right)$ is the average value for $\left(\left|a_{4}^{\prime}{ }^{U}-a_{1}^{\prime} U\right| \times y_{A_{U}^{\prime}}^{*}\right)$ and $\left(\left|a_{4}^{\prime L}-a_{1}^{\prime L}\right| \times y_{A_{L}^{\prime}}^{*}\right)$.

$\operatorname{CPS}_{I I}\left(A^{\prime}\right) \in[-1,1]$.

If $C P S_{I I}\left(A^{\prime}\right)>C P S_{I I}\left(B^{\prime}\right)$, then $A^{\prime} \succ B^{\prime}$. (i.e. $A^{\prime}$ is greater than $\left.B^{\prime}\right)$.

If $C P S_{I I}\left(A^{\prime}\right)<C P S_{I I}\left(B^{\prime}\right)$, then $A^{\prime} \prec B^{\prime}$. (i.e. $A^{\prime}$ is lesser than $\left.B^{\prime}\right)$.

If $C P S_{I I}\left(A^{\prime}\right)=C P S_{I I}\left(B^{\prime}\right)$, then $A^{\prime} \approx B^{\prime}$. (i.e. $A^{\prime}$ and $B^{\prime}$ is equal).

Note that, computations on finding the average in Step 3 are introduced in this methodology as to ensure only one ranking value for each type - II fuzzy number is obtained. This is because the average gives only one value of $x_{A^{\prime}}^{*}, y_{A^{\prime}}^{*}$ and $s\left(A^{\prime}\right)$ for each type - II fuzzy number under consideration even if two values of $x_{A^{\prime}}^{*}$, $y_{A^{\prime}}^{*}$ and $s\left(A^{\prime}\right)$ are computed in Step 1 and 2. It is worth adding that these computations on finding the average are generalisation of $\mathrm{Wu} \&$ Mendel (2009) work on ranking type - II fuzzy number using approximation to the end points of type - reduced interval (Greenfield \& Chiclana, 2013).

\section{Validation of Results}

In this section, two types of validations are used namely theoretical and empirical validation where both justify the utilisable of the CPS ranking method in decision making.

\subsection{Theoretical Validation}

For theoretical aspect, CPS ranking method is validated using four reasonable theoretical properties adopted from Wang \& Kerre $(2001,2002)$ whereby proofs of the properties are applicable to $C P S_{I I}$ ranking method. It is worth mentioning that this validation is crucial in order to ensure $C P S_{I I}$ ranking method is capable to ranking type - II fuzzy numbers appropriately. Without loss of generality, ordering properties presented by Wang \& Kerre $(2001,2002)$ which are provided for $C P S_{I I}$ ranking method are as follows.

Let $A_{1}^{\prime}$ and $A_{2}^{\prime}$ be two standardised generalised type - II fuzzy numbers where $A_{1}^{\prime}$ and $A_{2}^{\prime}$ can be any types of type - II fuzzy numbers.

Property 1: If $A_{1}^{\prime} \geqslant A_{2}^{\prime}$ and $A_{2}^{\prime} \geqslant A_{1}^{\prime}$, then $A_{1}^{\prime} \approx A_{2}^{\prime}$

\section{Proof:}

Since, $A_{1}^{\prime} \geqslant A_{2}^{\prime}$ implies that $C P S_{I I}\left(A_{1}^{\prime}\right) \geq C P S_{I I}\left(A_{2}^{\prime}\right)$, and $\tilde{A}_{2} \geqslant A_{1}^{\prime}$ implies that $C P S_{I I}\left(A_{2}^{\prime}\right) \geq C P S_{I I}\left(A_{1}^{\prime}\right)$ hence indicates that, $\operatorname{CPS}_{I I}\left(A_{1}^{\prime}\right)=\operatorname{CPS}_{I I}\left(A_{2}^{\prime}\right)$, which is $A_{1}^{\prime} \approx A_{2}^{\prime}$

Property 2: If $A_{1}^{\prime} \geqslant A_{2}^{\prime}$ and $A_{2}^{\prime} \geqslant A_{3}^{\prime}$, then $A_{1}^{\prime} \approx A_{3}^{\prime}$

\section{Proof:}

For $C P S_{I I}$ ranking method, $A_{1}^{\prime} \geqslant A_{2}^{\prime}$ implies that $C P S_{I I}\left(A_{1}^{\prime}\right) \geq C P S_{I I}\left(A_{2}^{\prime}\right)$, and $\tilde{A}_{2} \geqslant \tilde{A}_{3}$, implies that $\operatorname{CPS}_{I I}\left(A_{2}^{\prime}\right) \geq \operatorname{CPS}_{I I}\left(A_{3}^{\prime}\right)$.

This indicates that $\operatorname{CPS}_{I I}\left(A_{1}^{\prime}\right) \geq C P S_{I I}\left(A_{3}^{\prime}\right)$, which is $A_{1}^{\prime} \geqslant A_{3}^{\prime}$.

Property 3: If $A_{1}^{\prime} \cap A_{2}^{\prime}=\emptyset$ and $A_{1}^{\prime}$ is on the right side of $A_{2}^{\prime}$, then $A_{1}^{\prime} \geqslant A_{2}^{\prime}$

Proof:

Since, $A_{1}^{\prime} \cap A_{2}^{\prime}=\emptyset$ and $A_{1}^{\prime}$ is on the right side of $A_{2}^{\prime}$, hence, implies that $\operatorname{CPS}_{I I}\left(A_{1}^{\prime}\right) \geq C P S_{I I}\left(A_{2}^{\prime}\right)$, thus, $A_{1}^{\prime}$ $\geqslant A_{2}^{\prime}$.

Property 4: The order of $A_{1}^{\prime}$ and $A_{2}^{\prime}$ is not affected by the other type - II fuzzy numbers under comparison. 
Proof:

Since, the order of $A_{1}^{\prime}$ and $A_{2}^{\prime}$, is completely determined by $C P S_{I I}\left(A_{1}^{\prime}\right)$ and $C P S_{I I}\left(A_{2}^{\prime}\right)$ respectively, which indicates that it has nothing to do by the other type - II fuzzy numbers under comparison, thus, the ordering of $A_{1}^{\prime}$ and $A_{2}^{\prime}$ is not affected by the other type - II fuzzy numbers under comparison.

Based on all the above proofs provided in the theoretical validations, it is clear that the proposed $C P S_{I I}$ ranking method fulfils all properties of reasonable ordering for fuzzy quantities presented by Wang \& Kerre (2001, 2002). This is directly indicating that $C P S_{I I}$ ranking method is suitable and has the capability to ranking type - II fuzzy numbers appropriately.

\subsection{Empirical Validation}

In this validation, some benchmarking examples of interval type - II fuzzy numbers which are proposed for the first time in the literature of fuzzy sets. These benchmarking examples involve cases that are related with decision making problems. If a ranking method produces correct ranking result such that the result is consistent with human intuition, then the ranking result is signified as consistent (Y). Otherwise, it is inconsistent $(\mathrm{N})$.

It is worth mentioning here that all benchmarking examples considered in this study are in the form of standardised generalised type - II fuzzy numbers so that any cases of type - II fuzzy numbers which are suited with decision making environment.

Note that, all established existing ranking methods used in this section are methods proposed to ranking type - II fuzzy numbers. Otherwise mentioned, if methods are added with 'II' (e.g. II - Cheng (1998)), then this signifies that these methods are methods for ranking type - I fuzzy numbers but are extended to ranking interval type - II fuzzy number for the first time all interval type - II fuzzy numbers considered are reduced into type - I fuzzy numbers using Nie - Tan (2008) reduction method. The following are cases of interval type - II fuzzy number which potentially appear in decision making environment.

Case 1: Embedded type - II fuzzy numbers of different shapes.

Consider two type - II fuzzy numbers $A_{1}^{\prime}$ and $A_{2}^{\prime}$ shown in Figure 3. The correct ranking order of type II fuzzy numbers for this case should be $A_{1}^{\prime} \succ A_{2}^{\prime}$ due to the centroid of $A_{1}^{\prime}$ is greater than $A_{2}^{\prime}$. Chen \& Chen (2009) produced unreasonable ranking order that is inconsistent with human intuition ( $\left.A_{2}^{\prime} \succ A_{1}^{\prime}\right)$ since they treated type - II fuzzy numbers with smaller centroid as greater than the other. Kumar et al. (2010) and Chen \& Sanguansat (2011) ranking methods on the other hand treated both type - II fuzzy numbers as equal $\left(A_{1}^{\prime} \approx\right.$
$A_{2}^{\prime}$ ) which is inconsistent with human intuition. It is also shown in Table 1 where ranking methods by Cheng (1998) and Chu \& Tsao (2002) unable to give any ranking result for this case as they are only applicable to normal case of fuzzy numbers. This outcome implies that those methods are unable to differentiate the type II fuzzy numbers appropriately. Using $C P S_{I I}$ ranking method, the ranking order produces is consistent with Dat et al. (2012) method where it produces consistent ranking order as human intuition by ranking the type II fuzzy numbers with higher centroid as higher ranking order.

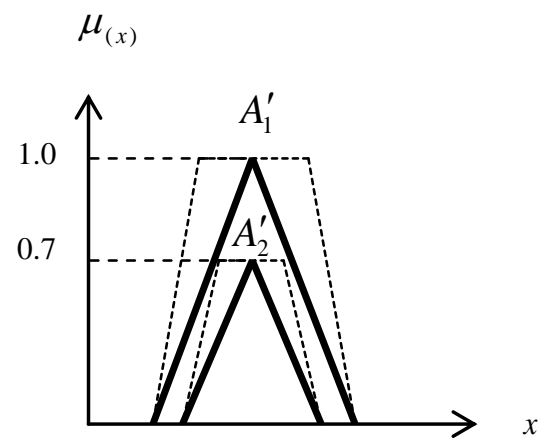

$\begin{array}{lll}0.1 & 0.3 & 0.5\end{array}$

$$
\begin{aligned}
A_{1}^{\prime} & =[(0.1,0.2,0.4,0.5 ; 1 ; 1),((0.2,0.25,0.35,0.4 ; 0.7 ; 0.7))] \\
A_{2}^{\prime} & =[(0.1,0.3,0.3,0.5 ; 1 ; 1),((0.2,0.3,0.3,0.4 ; 0.7 ; 0.7))]
\end{aligned}
$$

Fig 3: Type - II fuzzy numbers $A_{1}^{\prime}$ and $A_{2}^{\prime}$ of Case 1 .

Table 1: Comparative results using Type - II fuzzy

\begin{tabular}{|c|c|c|c|c|}
\hline \multirow{2}{*}{ Methods } & \multicolumn{2}{|c|}{$\begin{array}{c}\text { Type - II fuzzy } \\
\text { numbers }\end{array}$} & \multirow{2}{*}{$\begin{array}{l}\text { Ranking } \\
\text { Results }\end{array}$} & \multirow{2}{*}{$\begin{array}{l}\text { Eval- } \\
\text { uation }\end{array}$} \\
\hline & $A_{1}^{\prime}$ & $A_{2}^{\prime}$ & & \\
\hline II - Cheng (1998) & - & - & $\mathrm{x}$ & $\mathrm{N}$ \\
\hline II - Chu \& Tsao (2002) & - & - & $\mathrm{x}$ & $\mathrm{N}$ \\
\hline $\begin{array}{l}\text { II - Chen \& Chen } \\
\text { (2009) }\end{array}$ & 0.254 & 0.258 & $A_{1}^{\prime} \prec A_{2}^{\prime}$ & $\mathrm{N}$ \\
\hline II - Kumar et al. (2010) & 0.240 & 0.240 & $A_{1}^{\prime} \approx A_{2}^{\prime}$ & $\mathrm{N}$ \\
\hline $\begin{array}{l}\text { II - Chen \& Sanguansat } \\
\text { (2011) }\end{array}$ & 0.300 & 0.300 & $A_{1}^{\prime} \approx A_{2}^{\prime}$ & $\mathrm{N}$ \\
\hline II -Dat et al. (2012) & 0.333 & 0.222 & $A_{1}^{\prime} \succ A_{2}^{\prime}$ & $\mathrm{Y}$ \\
\hline$C P S_{I I}$ & 0.103 & 0.077 & $A_{1}^{\prime} \succ A_{2}^{\prime}$ & $\mathrm{Y}$ \\
\hline
\end{tabular}
numbers of Case 1.

\footnotetext{
Note: ' $\mathrm{x}$ ' denotes ranking method as unable to rank the type - II fuzzy numbers $\therefore$ denotes no ranking result are obtained.

' $\mathrm{Y}$ ' denotes the ranking result is consistent

' $\mathrm{N}$ ' denotes the ranking result is inconsistent.
}

Case 2: Embedded Type - II fuzzy numbers of different spreads

Consider two type - II fuzzy numbers $A_{1}^{\prime}$ and $A_{2}^{\prime}$ shown in Figure 4. The correct ranking order for this case IS $A_{2}^{\prime} \succ A_{1}^{\prime}$. This is due to ranking order for type II fuzzy numbers with lower spread value is greater than the other provided that the centroid value of type II fuzzy numbers under consideration are the same. In this case, Kumar et al. (2010), Allahviranloo \& Saneifard (2012) and Dat et al. (2012) ranking methods are 
unable to differentiate the type - II fuzzy numbers where they are producing equal ranking $\left(A_{1}^{\prime} \approx A_{2}^{\prime}\right)$. Cheng (1998) and Chu \& Tsao (2002) ranking methods in this case produce no ranking result as they both are not applicable when dealing with non - normal fuzzy numbers. Ranking method by $\mathrm{Yu}$ et al. (2013) on the other hand, capture the actual decision makers' preference by utilising the degree of optimisms in obtaining the ranking order for the type - II fuzzy numbers. $C P S_{I I}$ ranking method produces consistent ordering as Chen \& Chen (2009) and Chen \& Sanguansat (2011) in which all of them rank the type - II fuzzy numbers correctly by giving priority towards type - II fuzzy numbers with lower spread which is in line with human intuition.

It can also be seen in this case where most of the latest presented ranking methods were unable to solve this type of type - II fuzzy numbers case.

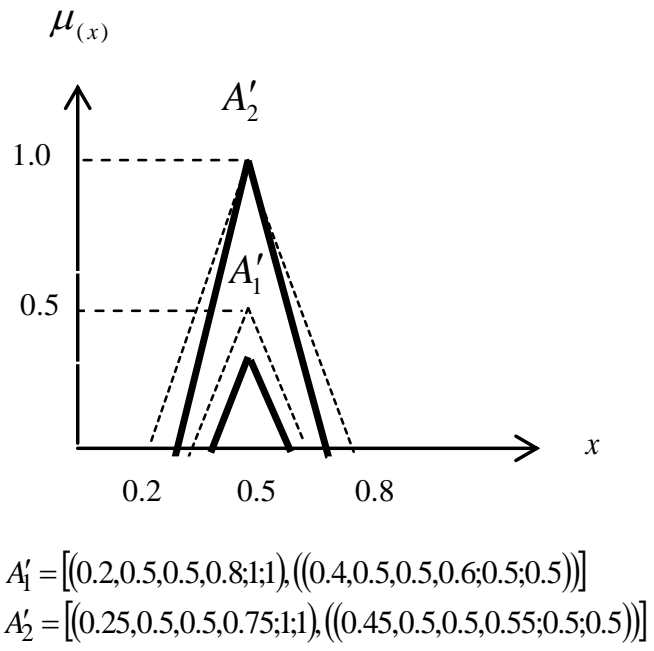

Fig 3: Type - II fuzzy numbers $A_{1}^{\prime}$ and $A_{2}^{\prime}$ of Case 2.

Table 2: Comparative results using Type - II fuzzy numbers of Case 2.

\begin{tabular}{|c|c|c|c|c|}
\hline \multirow{2}{*}{ Methods } & \multicolumn{2}{|c|}{$\begin{array}{l}\text { Type - II fuzzy } \\
\text { numbers }\end{array}$} & \multirow{2}{*}{$\begin{array}{l}\text { Ranking } \\
\text { Results }\end{array}$} & \multirow{2}{*}{$\begin{array}{c}\text { Eval } \\
\text { uati } \\
\text { on }\end{array}$} \\
\hline & $A_{1}^{\prime}$ & $A_{2}^{\prime}$ & & \\
\hline II - Cheng (1998) & - & - & $\mathrm{x}$ & $\mathrm{N}$ \\
\hline II - Chu \& Tsao (2002) & - & - & $\mathrm{x}$ & $\mathrm{N}$ \\
\hline II - Chen \& Chen (2009) & 0.258 & 0.278 & $A_{1}^{\prime} \prec A_{2}^{\prime}$ & $\mathrm{N}$ \\
\hline II - Kumar et al. (2010) & 0.500 & 0.500 & $A_{1}^{\prime} \approx A_{2}^{\prime}$ & $\mathrm{N}$ \\
\hline $\begin{array}{l}\text { II - Chen \& Sanguansat } \\
\text { (2011) }\end{array}$ & 0.300 & 0.300 & $A_{1}^{\prime} \approx A_{2}^{\prime}$ & $\mathrm{N}$ \\
\hline $\begin{array}{l}\text { II - Allahviranloo \& } \\
\text { Saneifard (2012) }\end{array}$ & 0.240 & 0.240 & $A_{1}^{\prime} \approx A_{2}^{\prime}$ & $\mathrm{N}$ \\
\hline II - Dat et al. (2012) & 0.111 & 0.111 & $A_{1}^{\prime} \approx A_{2}^{\prime}$ & $\mathrm{N}$ \\
\hline $\begin{array}{l}\text { II- Yu et al. (2013) for } \\
\alpha=0\end{array}$ & 1.000 & 1.000 & $A_{1}^{\prime} \prec A_{2}^{\prime}$ & $\mathrm{N}$ \\
\hline $\begin{array}{l}\mathrm{II}-\mathrm{Yu} \text { et al. (2013) for } \\
\alpha=0.5\end{array}$ & 1.000 & 1.000 & $A_{1}^{\prime} \approx A_{2}^{\prime}$ & $\mathrm{N}$ \\
\hline $\begin{array}{l}\text { II - Yu et al. (2013) for } \\
\alpha=1\end{array}$ & 1.000 & 1.000 & $A_{1}^{\prime} \succ A_{2}^{\prime}$ & $\mathrm{Y}$ \\
\hline$C P S_{I I}$ & 0.103 & 0.077 & $A_{1}^{\prime} \succ A_{2}^{\prime}$ & $\mathrm{Y}$ \\
\hline
\end{tabular}

Note: ' $\mathrm{Y}$ ' denotes the ranking result is consisten

' $\mathrm{N}$ ' denotes the ranking result is inconsistent.
Case 3: Reflection of Type - II fuzzy numbers.

Consider reflection case of two non - overlapping interval type - II fuzzy numbers $A_{1}^{\prime}$ and $A_{2}^{\prime}$ shown in Figure 5. It is obvious that $A_{2}^{\prime}$ is situated on the farthest right compared to $A_{1}^{\prime}$. Therefore, the ranking order that is consistent with human intuitions should be $A_{2}^{\prime}$ $\succ A_{1}^{\prime}$. Cheng (1998) and Chu \& Tsao (2002) ranking methods again producing no ranking result for this case while Kumar et al. (2010) method is incapable to differentiate both interval type - II fuzzy numbers, hence producing inconsistent ranking order. Using the $C P S_{I I}$ method, the ranking order obtained is consistent with Chu \& Tsao (2002), Chen \& Chen (2009), Chen \& Sanguansat (2011), Allahviranloo \& Saneifard (2012) and Dat et al. (2012) in which the ranking order was consistent with human intuitions.

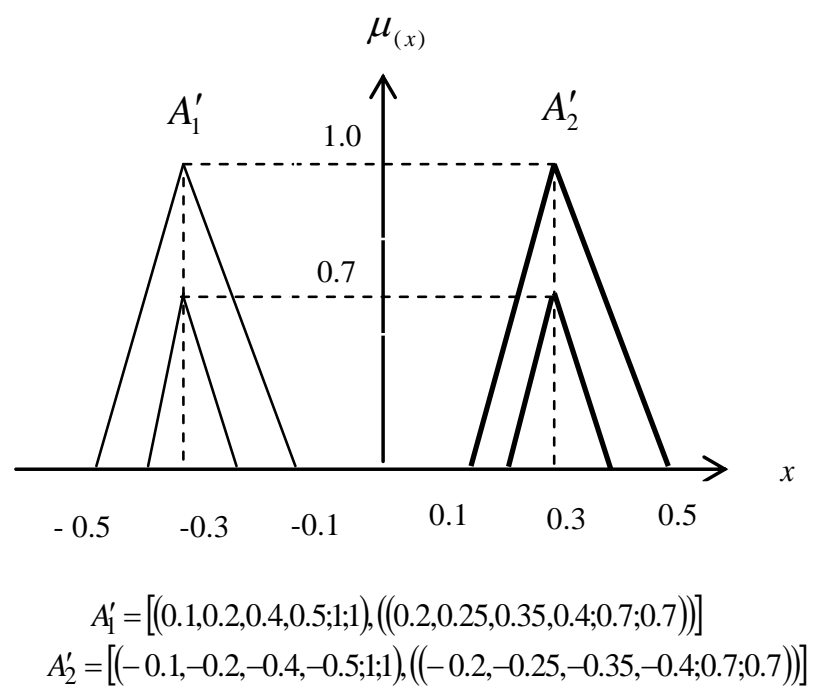

Fig 5: Type - II fuzzy numbers $A_{1}^{\prime}$ and $A_{2}^{\prime}$ of Case 3 .

Table 3: Comparative results using Type - II fuzzy numbers of Case 3

\begin{tabular}{|c|c|c|c|c|}
\hline \multirow{2}{*}{ Methods } & \multicolumn{2}{|c|}{$\begin{array}{c}\text { Type - II fuzzy } \\
\text { numbers }\end{array}$} & \multirow{2}{*}{$\begin{array}{l}\text { Ranking } \\
\text { Results }\end{array}$} & \multirow{2}{*}{$\begin{array}{l}\text { Evalu- } \\
\text { ation }\end{array}$} \\
\hline & $A_{1}^{\prime}$ & $A_{2}^{\prime}$ & & \\
\hline II - Cheng (1998) & - & - & $\mathrm{x}$ & $\mathrm{N}$ \\
\hline $\begin{array}{l}\text { II - Chu \& Tsao } \\
(2002)\end{array}$ & - & - & $\mathrm{x}$ & $\mathrm{Y}$ \\
\hline $\begin{array}{l}\text { II - Chen \& Chen } \\
\text { (2009) }\end{array}$ & -0.258 & 0.258 & $A_{1}^{\prime} \prec A_{2}^{\prime}$ & $\mathrm{Y}$ \\
\hline $\begin{array}{l}\text { II - Kumar et al. } \\
(2010)\end{array}$ & 0 & 0 & $A_{1}^{\prime} \approx A_{2}^{\prime}$ & $\mathrm{N}$ \\
\hline $\begin{array}{l}\text { II - Chen \& San- } \\
\text { guansat (2011) }\end{array}$ & -0.300 & 0.300 & $A_{1}^{\prime} \prec A_{2}^{\prime}$ & $\mathrm{Y}$ \\
\hline II -Dat et al. (2012) & 0.150 & 0.133 & $A_{1}^{\prime} \succ A_{2}^{\prime}$ & $\mathrm{N}$ \\
\hline $\begin{array}{l}\text { II - Allahviranloo \& } \\
\text { Saneifard (2012) }\end{array}$ & 0.240 & 0.240 & $A_{1}^{\prime} \prec A_{2}^{\prime}$ & $\mathrm{N}$ \\
\hline$C P S_{I I}$ & 0 & 0.600 & $A_{1}^{\prime} \prec A_{2}^{\prime}$ & $\mathrm{Y}$ \\
\hline
\end{tabular}

Note: ' $\mathrm{Y}$ ' denotes the ranking result is consistent ' $\mathrm{N}$ ' denotes the ranking result is inconsistent. 
Case 4: Non - overlapping Type - II fuzzy numbers of different shapes

Consider different shape case of two non - overlapping type - II fuzzy numbers $A_{1}^{\prime}$ and $A_{2}^{\prime}$ shown in Figure 6. Using the same explanation in Case 3, the ranking order should be obtained is $A_{2}^{\prime} \succ A_{1}^{\prime}$. Apart from that, another reason of $A_{2}^{\prime} \succ A_{1}^{\prime}$ is because a crisp value is treated greater than any type - II fuzzy numbers (Chen \& Chen, 2009). Only certain ranking methods are able to rank these type - II fuzzy numbers that is consistent with human intuitions. They are Chen \& Chen (2009), Chen \& Sanguansat (2011), Dat et al. (2012) and the $C P S_{I I}$ ranking method. Therefore, this situation shows that $C P S_{I I}$ ranking method not only able to give consistent ranking order towards type - II fuzzy numbers but also to crisp value.

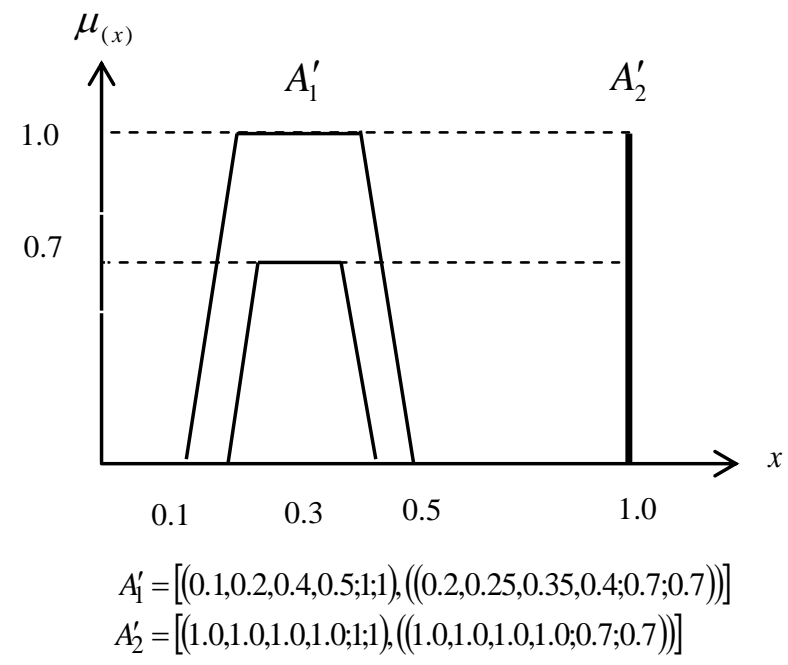

Fig 6: Type - II fuzzy numbers $A_{1}^{\prime}$ and $A_{2}^{\prime}$ of Case 4 .

Table 4: Comparative results using Type - II fuzzy numbers of Case 4.

\begin{tabular}{|c|c|c|c|c|}
\hline \multirow{2}{*}{ Methods } & \multicolumn{2}{|c|}{$\begin{array}{c}\text { Type - II fuzzy } \\
\text { numbers }\end{array}$} & \multirow{2}{*}{$\begin{array}{c}\text { Ranking } \\
\text { Results }\end{array}$} & \multirow{2}{*}{$\begin{array}{c}\text { Eval } \\
\text { uatio } \\
\text { n }\end{array}$} \\
\hline & $A_{1}^{\prime}$ & $A_{2}^{\prime}$ & & \\
\hline II - Cheng (1998) & $\mathrm{X}$ & $\mathrm{x}$ & - & $\mathrm{N}$ \\
\hline $\begin{array}{l}\text { II - Chu \& Tsao } \\
(2002)\end{array}$ & $\mathrm{x}$ & $\mathrm{x}$ & - & $\mathrm{N}$ \\
\hline $\begin{array}{l}\text { II - Chen \& Chen } \\
(2009)\end{array}$ & 0.254 & 0.258 & $A_{1}^{\prime} \prec A_{2}^{\prime}$ & Y \\
\hline $\begin{array}{l}\text { II - Kumar et al. } \\
(2010)\end{array}$ & $\mathrm{x}$ & $\mathrm{x}$ & - & $\mathrm{N}$ \\
\hline $\begin{array}{l}\text { II - Chen \& San- } \\
\text { guansat (2011) }\end{array}$ & 0.300 & 1 & $A_{1}^{\prime} \prec A_{2}^{\prime}$ & $\mathrm{N}$ \\
\hline II -Dat et al. (2012) & $\mathrm{x}$ & $\mathrm{x}$ & - & $\mathrm{N}$ \\
\hline$C P S_{I I}$ & 0.333 & 1.082 & $A_{1}^{\prime} \prec A_{2}^{\prime}$ & $\mathrm{Y}$ \\
\hline
\end{tabular}

\footnotetext{
Note: ' $x$ ' denotes ranking method as unable to rank the type - II fuzzy numbers '-" denotes no ranking result are obtained.

' $\mathrm{Y}$ ' denotes the ranking result is consistent ' $\mathrm{N}$ ' denotes the ranking result is inconsistent.
}

It is notable that each presented method of ranking type - II fuzzy numbers has its own strengths and weaknesses. Although, all methods used for comparing type - II fuzzy numbers in this section were actually methods for ranking fuzzy numbers, the above analysis was provided as to illustrate the capability of the established ranking methods in ranking type - II fuzzy numbers rather than ranking fuzzy numbers only. Based on the analysis, there were some methods that can deal with cases of fuzzy numbers effectively while some produce irrelevant results for certain cases. Nevertheless, in each case examined above, the $C P S_{I I}$ ranking method is the most effective in ranking type - II fuzzy numbers by giving consistent ranking results for all cases of type - II fuzzy numbers.

Since, both layers of the proposed methodology have been validated, hence, this implies that the proposed methodology is relevant and reliable for solving real decision making problems involving type - II fuzzy numbers.

\section{Conclusion}

This study proposes a novel method for ranking type - II fuzzy numbers which utilises centroid point and spread approaches, $C P S_{I I}$. In this paper, it is shown that the $C P S_{I I}$ ranking methodology is validated and produces results that are correct such that the results are consistent with human intuition. Furthermore, the utilisation of standardised generalised type - II fuzzy numbers in replacing conventional type - II fuzzy numbers used by existing method improve the ability of type - II fuzzy numbers when being applied to decision making problems. In conclusion, the proposed method possesses intuitional concepts for ranking type - II fuzzy numbers as well as for decision making analysis. Therefore, it is expected that this method can be further improved for decision making purposes.

\section{References}

A. Asady, The Revised Method of Ranking LR Fuzzy Numbers Based on Deviation Degree, Expert Systems with Applications, 37:5056--5060, 2010.

A. Kumar, P. Singh, P. Kaur and A. Kaur. A New Approach for Ranking Generalized Trapezoidal Fuzzy Numbers, World Academy of Science, Engineering and Technology, 68: 229--302, 2010.

A. S. A. Bakar and A. Gegov, Ranking of fuzzy numbers based centroid point and spread, Journal of Intelligent and Fuzzy Systems, 27:1179--1186, 2014.

A. S. A. Bakar, D. Mohamad and N. H. Sulaiman, Distance - Based Ranking Fuzzy Numbers, Advances in Computational Mathematics and Its Applications, 1(3):146--150, 2012.

A. S. A. Bakar, D. Mohamad and N. H. Sulaiman, Ranking Fuzzy Numbers using Similarity Measure with Centroid, IEEE International Conference on Science and Social Research, 58--63, 2010. 
C. H. Cheng, A New Approach for Ranking Fuzzy Numbers by Distance Method, Fuzzy Sets and System, 95: 307--317, 1998.

C. T. Chu and C.T. Tsao, Ranking Fuzzy Numbers with an Area Between the Centroid Point and Original Point, Computer and Mathematics with Applications, 43:111--117, 2002.

D. Wu and J - M. Mendel, A Comparative Study of Ranking Methods, Similarity Measures and Uncertainty Measures for Interval Type - 2 Fuzzy Sets, Information Sciences, 179:1169--1192, 2009.

$\mathrm{H}$ - J, Zimmermann, An application - oriented view of modelling uncertainty, European Journal of Operational Research, 122: 190--198, 2000.

H. B. Mitchel, Ranking Type - 2 Fuzzy Numbers, IEEE Transactions on Fuzzy Systems, 14(2):287-294, 2006.

H. Deng, Comparing and ranking fuzzy numbers using ideal solutions, Applied Mathematical Modelling, 38:1638--1646, 2014.

J. Hu, Y. Zhang, X. Chen and Y. Liu, Multi - Criteria Decision Making Method Based on Possibility Degree of Interval Type - 2 Fuzzy Number, Knowledge - Based Systems, 43:21--29, 2013.

J. M. Mendel, R. I. John and F. L. Liu, Interval type2 fuzzy logical systems made simple, IEEE Transactions on Fuzzy Systems, 4:808--821, 2006.

K. Nagy and M. Takács, Type - 2 Fuzzy Sets and SSAD As A Possible Application, Acta Polytechnica Hungarica, 5:111--120, 2008.

L. A. Zadeh, Fuzzy sets. Information Control, 8:338$-356,1965$.

L. A. Zadeh, The Concept of A Linguistic Variable and Its Application to Approximate Reasoning, Part 1, 2 and 3, Information Sciences, 8:199--249, 1975.

L. Q. Dat, V. F. Yu and S. Y. Chou, An Improved Ranking Method for Fuzzy Numbers Based on the Centroid Index, International Journal of Fuzzy Systems, 14(3):413--419, 2012.

M. L. Wang, H. F. Wang and L. C. Lung, Ranking Fuzzy Number Based on Lexicographic Screening Procedure, International Journal of Information Technology and Decision Making, 4:663--678, 2005.
M. Nie and W. W. Tan, Towards An Efficient TypeReduction Method For Interval Type-2 Fuzzy Logic Systems, Proceedings of FUZZ-IEEE 2008, Hong Kong, pages 1425-1432, 2008.

R. I. John, P. R. Innocent, and M. R. Barnes, Neurofuzzy clustering of radiographic tibia image data using type-2 fuzzy sets. Information Sciences, 125:203--220, 2000.

R. Jain, Decision-Making In The Presence of Fuzzy Variable, IEEE Transactions on Man and Cybernetic 6: 698--703, 1976.

S. Greenfield and F. Chiclana, Accuracy and Complexity Evaluation of Defuzzification Strategies for the Discretised Interval Type - 2 Fuzzy Set, International Journal of Approximate Reasoning, 54(8):1013--1033, 2013.

S. M. Chen and J. H. Chen, Fuzzy Risk Analysis Based on Ranking Generalized Fuzzy Numbers with Different Heights and Different Spreads, Expert Systems with Applications, 36:6833--6842, 2009.

S. M. Chen and K. Sanguansat, Analyzing fuzzy risk based on a new fuzzy ranking method between generalized fuzzy numbers, Expert System with Applications, 38:2163--2171, 2011.

T. Allahviranloo and R. Saneifard. Defuzzification Method for Ranking Fuzzy Numbers based on Center of Gravity. Iranian Journal of Fuzzy Systems 9 (6), pp. 57-67, 2012.

T. S. Wallsten and D.V. Budescu, A Review of Human Linguistic Probability Processing: General Principles and Empirical Evidence, The Knowledge Engineering Review, 10(1):43--62, 1995.

V. F. Yu, H. T. X Chi and C. W. Shen, Ranking Fuzzy Numbers based on Epsilon - Deviation Degree, Applied Soft Computing, 13(8):3621-3627,2013.

X. Wang and E. E. Kerre, Reasonable Propeties for the Ordering of Fuzzy Quantities (I), Fuzzy Sets and Systems, 118:375--385, 2001.

X. Wang and E. E. Kerre, Reasonable Propeties for the Ordering of Fuzzy Quantities (II), Fuzzy Sets and Systems, 118:387--405, 2002. 